\title{
Anaerobic Filter Treatment of Landfill-Leachate Using Low-Cost Filter Materials
}

\author{
B.S.R. Nanayakkara, W.K.C.N. Dayanthi, H.M.L.V.K. Herath, K.H.S.S. Tharanga \\ and K. Kawamoto
}

\begin{abstract}
Anaerobic-filters are quite expensive due to the high-cost of artificial filtration media. Hence, introducing alternative low-cost filtration media will make anaerobic-filters more economical. The aim of this study was to investigate the performances of several low-cost/waste materials as filtration media in anaerobic-filters to treat organic compounds, nutrients and heavy metals found in landfill-leachate. The experimental set-up consisted of four down-flow anaerobic-filter columns, two of which were control columns while the others were experimental columns. The control columns were filled with Granular Activated Carbon (GAC) and Plastic Pall Rings (PPR) as single medium. The experimental columns were filled with a mixture of Dewatered Alum Sludge (DAS), Washed Sea Sand (WSS), Firewood Charcoal (FWC), while the other with the same materials as layers. During the application of $10 \%$ diluted landfill-leachate within a period of 115 days, the overall removal efficiencies of the filter bed with layered-media were $73 \%, 84 \%, 61 \%, 55 \%, 76 \%$ and $79 \%$ for COD, $\mathrm{BOD}_{5}, \mathrm{TN}$, Ammonia-N $\left(\mathrm{NH}_{3}-\mathrm{N}\right), \mathrm{TP}$ and Orthophosphate-P $\left(\mathrm{PO}_{4}^{3-}-\mathrm{P}\right)$, respectively. The filter bed with mixed-media gave the overall removal efficiencies of $59 \%, 87 \%, 49 \%, 26 \%, 71 \%$ and $78 \%$ for $\mathrm{COD}, \mathrm{BOD}_{5}, \mathrm{TN}, \mathrm{NH}_{3}-\mathrm{N}, \mathrm{TP}$ and $\mathrm{PO}_{4}^{3-}-\mathrm{P}$, respectively. The experimental columns showed significant removal efficiencies for heavy metals, namely $\mathrm{Pb}(40 \%), \mathrm{Cd}(48 \%), \mathrm{Cu}(41 \%)$ and $\mathrm{Mn}(52 \%)$ in the mixed-media column and (54\%), Cd (37\%), Cu (54\%) and Mn (57\%) in the layered-media column.
\end{abstract}

Keywords: Aanaerobic filters, Filter materials, Landfill-leachate, Organic compounds, Nitrogenous compounds, Heavy metals

\section{Introduction}

Nowadays, municipal solid waste (MSW) generation has become faster with the increase of the growth of population, industrial development and complexity of the requirements of the human beings. Therefore, open dumps and unregulated landfills have become common sites in developing countries in particular, threatening the ecology.

Landfill-leachate is generated as a result of percolation of rain water and moisture through waste in landfills [1]. The landfill-leachate may have several contaminants like organic matter, nitrogenous and phosphorus compounds, heavy metals like $\mathrm{Fe}, \mathrm{Zn}, \mathrm{Pb}, \mathrm{Cu}, \mathrm{Cd}, \mathrm{Cr}$ and chlorinated organic and inorganic salts [2], [3], [4]. Heavy metals can cause serious water pollution and threaten the environment, while biodegradable organic matter and ammonianitrogen may consume the dissolved oxygen required for aquatic organisms [5]. Hence, if the landfill-leachate is released untreated, it will be hazardous to ground and surface water. Therefore, landfill-leachate needs to be pretreated to meet the standards for its discharge into the sewer or its direct disposal into surface water [6].

Ms. B.S.R. Nanayakkara, BSc (Eng) (Moratuwa), MPhil Candidate, Department of Civil $\mathcal{E}$ Environmental Engineering, Faculty of Engineering, University of Ruhuna, Sri Lanka. Civil Engineer (Ex Grade 1), Sri Lanka Ports Authority, Magalle, Galle.

Email: subhaninanayakkara6@gmail.com http://orcid.org/0000-0003-2984-6627

Eng. (Dr.) (Mrs) W.K.C.N.Dayanthi, BSc (Eng) (Hons) (Peradeniya); MEng (Moratuwa); MEng (AIT-Thailand); DEng (Kyoto-Japan), Senior Lecturer (Gr. 1), Department of Civil \& Environmental Engineering, Faculty of Engineering, University of Ruhuna.

Email:neetha02@gmail.com

http://orcid.org/0000-0003-3309-8430

Ms. H.M.L.V.K. Herath, BSc (Eng) (Ruhuna), Irrigation Engineer, Mahaweli Authority of Sri Lanka. Email: lakshivinu@gmail.com

http://orcid.org/0000-0002-2751-4066

Mr. K.H.S.S. Tharanga, BSc (Eng) (Ruhuna), Site Engineer, Nawaloka Piling (Pvt) Ltd.

Email: tsumindu@gmail.com http://orcid.org/0000-0003-4025-1026

Prof. K. Kawamoto, Ph.D. (University of Tokyo-Japan), Professor, Department of Civil \& Environmental Engineering, Saitama University, Japan. Email:kawamoto@mail.saitama-u.ac.jp (iD) $h t t p: / / o r c i d . o r g / 0000-0002-0695-5380$ 
Landfill-leachate treatment depends on its characteristics like volumetric flow rate and composition [2], [7]. The characteristics of the landfill-leachate may vary with several factors [2], [5]. There are several researchers who have attempted to solve the landfill-leachate problem and come up with some innovative treatment methods. These treatments can be classified as physical, chemical and biological treatments [4]. Conventional leachate treatment methods are very expensive, complex and often require multiple processes [4]. Therefore, the need for an effective and low-cost treatment has arisen.

Anaerobic filter is a notable "pump and treat method" because it is a kind of anaerobic digester containing a filter media that anaerobic bacteria can grow in as well as degrade organic compounds [8]. In the biological treatment, what is done is controlling the environmental condition to achieve an optimum growth of involved microorganisms. They are the ones who degrade the amount of colloidal, dissolved carbonaceous organic matter and inorganic compounds [4]. As Municipal Solid Waste (MSW) is high in organic content, biological treatment with attached growth anaerobic filters (AFs) suits well for the treatment of the leachate derived from MSW landfills. This process is widely used because it reduces the volume and mass of the input materials and generates useful byproducts as well.

However, AFs have become an expensive treatment method due to their expensive filter media. An introduction of efficient waste/lowcost, locally and readily available filter materials as packing media in anaerobic filters will enhance its applicability in landfill-leachate treatment. There is little research carried out on laboratory column experiments for landfillleachate treatment with anaerobic filters filled with such materials, and promising results have been obtained [9]. Dayanthi et al. [12] found that the organic media, namely coconut coir fiber (CCF), rice husk (RH), rice straw (RS) and saw chips (SC) packed in separate up-flow and down-flow anaerobic filter columns, were satisfactory in treating landfill-leachate, with different media emerging as the best for different contaminants. Nanayakkara et al. [10] found that the same organic materials (i.e. $\mathrm{CCF}, \mathrm{RH}, \mathrm{RS}, \mathrm{SC}$ ) as layers in one medium and several other waste materials, namely Dewatered Alum Sludge (DAS), Sea Sand (SS), Firewood Charcoal (FWC), filled as single medium in separate experimental columns, showed different capacities in removing contaminants represented by the conventional wastewater parameters. Nanayakkara et al. [11] concluded that the filtration media with the mixture of these FWC, SS and DAS show a high potential in removing Total-N and BOD, while having a low potential in removing COD in both up and down flow. This showed satisfactory performance in order for it to be used as a medium to treat the landfill-leachate. There, it has been deduced that a down-flow anaerobic filter packed with a mixture of SS, DAS and FWC can have an efficiency being on a par with an up flow anaerobic filter. This is a significant finding given that the operational cost of the down-flow system being lower than that of the up-flow system. A field-scale study conducted by Dayanthi et al. [13] showed that the inorganic materials, namely SS, DAS, Bio Char (BC), which is solid charcoal produced from heating plant matter and Saw Dust (SD) packed in layers in an $\mathrm{AF}$, perform on a par with an AF filled with the conventional medium (Plastic Pall Rings, PPR) in removing $\mathrm{COD}, \mathrm{BOD}_{5}$, nitrogenous compounds, cations and heavy metals.

Hence, the present study was carried out to investigate the treatment potential of selected waste/low-cost materials as filter media in AFs to treat the landfill-leachate. The objectives were to determine the treatment efficiencies and to compare the treatment efficiencies of the selected filter materials with those of the conventional expensive filter materials, and to study the variation of the physical and mechanical properties of the selected materials due to the interaction with landfill-leachate.

\section{Methodology}

\subsection{Overall Procedure}

The experimental set-up consisted of four laboratory-scale down-flow anaerobic filter columns. Two columns were used as control columns while others were experimental columns. One experimental column was filled with a mixture of DAS, FWC, WSS, and the other was filled with the same filter materials as layers. Control units were filled with GAC and PPR individually. The material properties were checked for all the filter columns at the beginning before the experimental run. Influent and effluent samples were collected every 5day period and tested for nutrients, organic matter and several heavy metals. The duration of the experimental run was 115 days. At the end of the experimental run, final material properties were tested. Overall removal 
efficiencies were obtained by conducting mass balance analyses.

\section{$2.2 \quad$ Experimental Set-Up}

Each filter column of $1.5 \mathrm{~m}$ height was made of PVC pipes having a $90 \mathrm{~mm}$ inner diameter. The height of the packed bed was $1.2 \mathrm{~m}$ and two perforated plates were placed on top and at the bottom of the packed bed, avoiding channeling leachate through the media from the top plate and preventing dropping and blocking media into down pipes by the bottom plate. A gas collection port was connected to the uppermost cap of each column. A $150 \mathrm{~mm}$ thick gravel layer was placed below the packed bed of each column to avoid clogging.

Figure 1 is an isometric view of the experimental set-up, Figure 2 is the sectional elevation of a filter column, and Figure 3 an image of it. The filter columns were arranged in different configurations. The selected low-cost filter materials, FWC, DAS, WSS. GAC and PPR, were used as filter materials in control columns. Figure 4 shows the filter materials. All the materials were washed and dried before filling in columns. FWC and DAS were crushed and sieved. First column was filled by a mixture of filter materials, namely FWC, WSS and DAS. The second column was filled with the same materials as layers of equal thickness $(400 \mathrm{~mm})$ in the order of FWC, DAS and WSS in the downward direction. The third and fourth columns were filled with GAC and PPR, respectively. Table 1 depicts the material mixing proportions and packing densities. The material mixing was done on volume basis. An overhead influent tank was placed at a higher elevation than that of the filter columns to store $10 \%$ diluted leachate, and the leachate was set to drop down to each column under gravity.

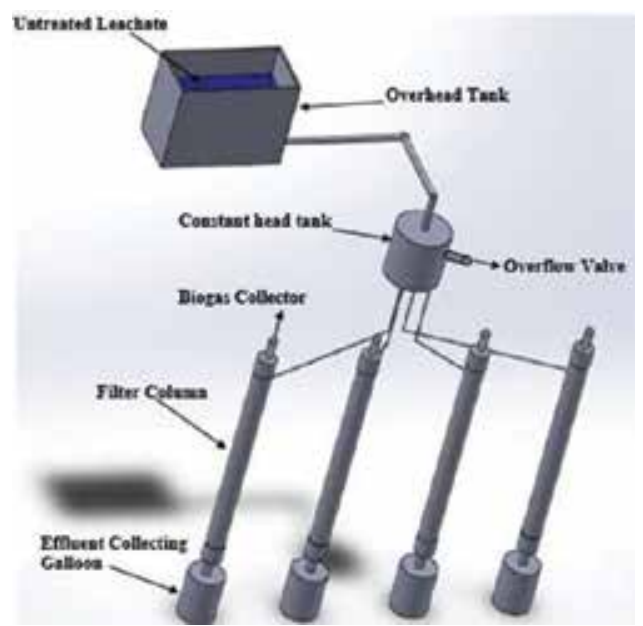

Figure 1 - Isometric View of the Experimental Set-Up
Table 1 - Material Mixing Proportions and Packing Densities

\begin{tabular}{|c|c|c|c|c|}
\hline $\begin{array}{c}\text { Column } \\
\text { Type }\end{array}$ & $\begin{array}{c}\text { Filter } \\
\text { Material }\end{array}$ & $\begin{array}{c}\text { Weight } \\
(\mathrm{g})\end{array}$ & $\begin{array}{c}\text { Volume } \\
\left(\mathrm{cm}^{3}\right)\end{array}$ & $\begin{array}{c}\text { Packing } \\
\text { Density } \\
\left(\mathrm{g} / \mathrm{cm}^{3}\right)\end{array}$ \\
\hline \multirow{3}{*}{ Mixture } & FWC & 773 & \multirow{2}{*}{7634.1} & 0.88 \\
\cline { 2 - 3 } & DAS & 2200 & & \\
\cline { 2 - 3 } Layered & WSS & 3758 & & 0.27 \\
\cline { 2 - 5 } & FWC & 683 & 2544.7 & 0.86 \\
\cline { 2 - 5 } & DSS & 2200 & 2544.7 & 0.48 \\
\hline GAC & GAC & 3758 & 2544.7 & 1.48 \\
\hline PPR & PPR & 1533 & 7634.1 & 0.4 \\
\hline
\end{tabular}

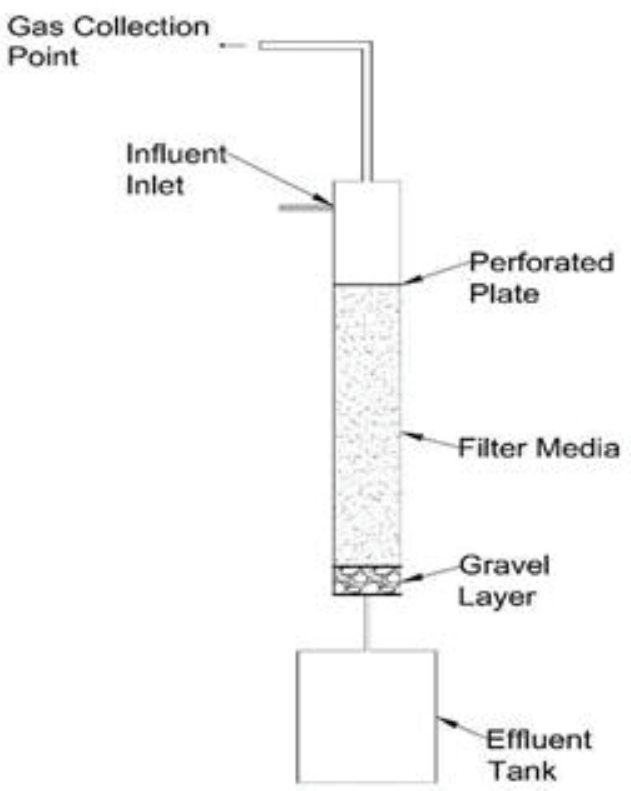

Figure 2 - Sectional Elevation of a Filter Column

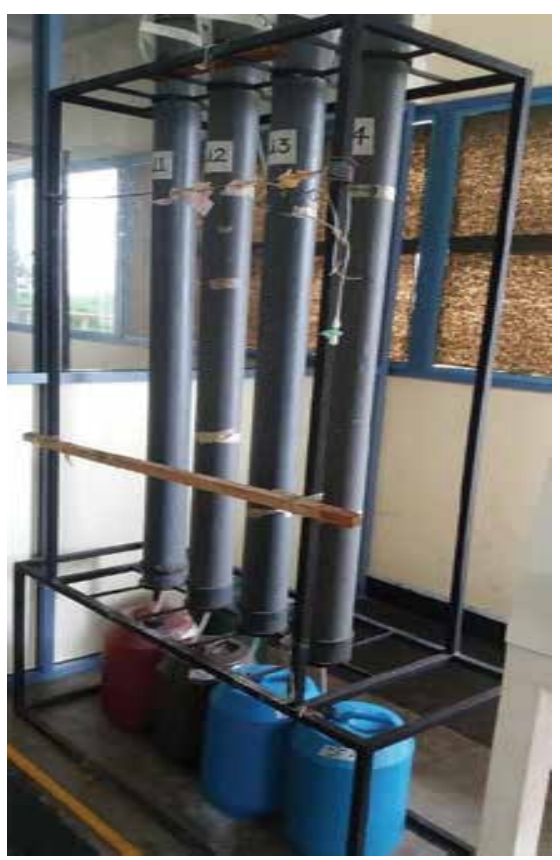

Figure 3 - An Image of the Experimental Set-Up 


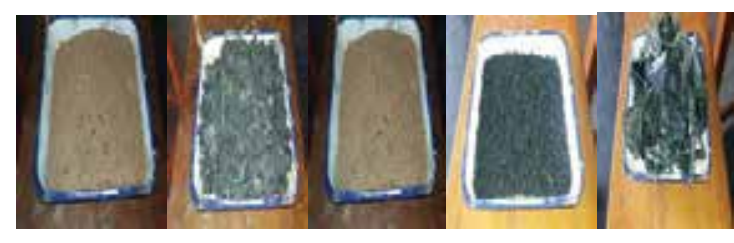

Figure 4 - Selected Filter Materials

\subsection{Experimental Run}

Leachate was collected from the ditch surrounding the Galle Municipal Council dumpsite at Heenpandala, in which leachate from everywhere of the dumpsite accumulates. Grab samples were collected from several locations of the ditch and all samples were mixed together. Then, the initial contaminant concentration was measured by diluting the leachate by $10 \%$ (Table 2). In order to minimize the errors of the significant changes in the leachate characteristics throughout the experimental run, the raw leachate was kept in a refrigerator until it was filled in the influent tank of the experimental set-up. Hence, the leachate was diluted 10 times because of the practical difficulties, otherwise would have arisen due to the need for refrigerating a large volume. Dilution was also a requirement to cope with the available treatment capacity of a laboratory-scale reactor. Since, the influent characteristics affect the treatment, the results would have been somewhat different if raw leachate had been the influent. However, given the $\mathrm{AF}$ reactor used in the present study being a laboratory-scale one, results would not have deviated much with that of a large-scale reactor on actual scale. Tables 3 and 4 show the mass loading rates of conventional parameters and heavy metals, respectively.

Table 2 - Influent Characteristics

\begin{tabular}{|c|c|}
\hline Parameter & $\begin{array}{l}\text { Influent } \\
\text { Concentration }\end{array}$ \\
\hline COD & $312.7 \mathrm{mg} / \mathrm{L}$ \\
\hline BOD 5 & $35.0 \mathrm{mg} / \mathrm{L}$ \\
\hline $\mathrm{TN}$ & $348.3 \mathrm{mg} / \mathrm{L}$ \\
\hline $\mathrm{TP}$ & $265.0 \mu \mathrm{g} / \mathrm{L}$ \\
\hline Orthophosphate-P & $221.0 \mu \mathrm{g} / \mathrm{L}$ \\
\hline Ammonia-N & $28.7 \mathrm{mg} / \mathrm{L}$ \\
\hline Nitrate-N & $110.9 \mathrm{mg} / \mathrm{L}$ \\
\hline Total Alkalinity & $500.0 \mathrm{mg} / \mathrm{L} \mathrm{as} \mathrm{CaCO} 3$ \\
\hline ORP & $372.1 \mathrm{mV}$ \\
\hline Conductivity & $3.7 \mathrm{mS} / \mathrm{cm}$ \\
\hline $\mathrm{TDS}$ & $1.1 \mathrm{mg} / \mathrm{L}$ \\
\hline $\mathrm{Pb}$ & $7.2 \mu \mathrm{g} / \mathrm{L}$ \\
\hline $\mathrm{Cd}$ & $0.7 \mu \mathrm{g} / \mathrm{L}$ \\
\hline $\mathrm{Cu}$ & $15.8 \mathrm{\mu g} / \mathrm{L}$ \\
\hline $\mathrm{Mn}$ & $33.9 \mu \mathrm{g} / \mathrm{L}$ \\
\hline
\end{tabular}

Table 3 - Mass Loading Rates of Conventional Parameters

\begin{tabular}{|c|c|c|}
\hline Parameter & $\begin{array}{l}\text { Average SLR } \\
\left(\mathrm{kg} / \mathrm{m}^{2} . \mathrm{d}\right)\end{array}$ & $\begin{array}{c}\text { Average VLR } \\
\left(\mathrm{kg} / \mathrm{m}^{3} . \mathrm{d}\right)\end{array}$ \\
\hline $\mathrm{COD}$ & 0.08 & 0.07 \\
\hline $\mathrm{BOD}_{5}$ & 0.02 & 0.02 \\
\hline $\mathrm{TN}$ & 0.12 & 0.1 \\
\hline $\mathrm{TP}$ & 0.03 & 0.02 \\
\hline
\end{tabular}

Table 4 - Mass Loading Rates of Heavy Metals

\begin{tabular}{|c|c|}
\hline Parameter & SLR $\left(\mu \mathrm{g} / \mathrm{m}^{2} \cdot \mathrm{d}\right)$ \\
\hline $\mathrm{Pb}$ & 2.5 \\
\hline $\mathrm{Cd}$ & 0.3 \\
\hline $\mathrm{Cu}$ & 5.4 \\
\hline $\mathrm{Mn}$ & 11.7 \\
\hline
\end{tabular}

The application of influent was in the downward direction for 115 days. During the experimental run, influent samples were collected from the overhead tank and effluent samples were collected from all the columns, every five-day time period. Characterization was carried out in terms of several wastewater parameters as per the Standard Methods for the Examination of Water and Wastewater [14].

Overall removal efficiencies were calculated using mass balance analysis. The treatment efficiencies of the experimental filter materials were compared with those of the control filter materials. According to the theory of mass balance analysis, the removed mass of the concerned parameter should be equal to the difference of mass of the concerning parameter in influent and effluent. This theory can be written in a formula as below:

Removed mass by the treatment $=$ mass of the parameter at the influent - mass in the effluent. Mass of each parameter could be obtained by multiplying the concentration by the volume. The physical properties such as particle size distribution, specific gravity and void volume ratio were measured at the beginning and end of the experimental run, while measuring mechanical properties, namely hydraulic conductivity and shear strength of core samples.

The average flow rate of the influent was maintained at $0.025 \mathrm{~mL} / \mathrm{s}$ using control valves. The pore volume Hydraulic Retention Time (HRT) and hydraulic loading rate for the filter columns were $2 \mathrm{~d}$ and $0.3 \mathrm{~m}^{3} / \mathrm{m}^{2} . \mathrm{d}$, 
respectively. Pore volume HRT was calculated by multiplying the filtration bed volume by the void volume ratio and dividing the multiplication by the average flow rate. Unsaturated conditions prevailed inside the filtration bed.

\section{Results and Discussion}

\subsection{Removal of Organic Compounds}

The removal efficiencies of the organic matter were determined in terms of $\mathrm{BOD}_{5}$ and $\mathrm{COD}$. $\mathrm{BOD}_{5}$ and $\mathrm{COD}$ are indicators of the organic impurities which are present in the wastewater. Attached growth processes in wastewater treatment are very effective for $\mathrm{BOD}_{5}$ removal and denitrification. Young et al. [15] explained the potential of the anaerobic filter process by successfully treating medium strength wastewater. Figures 5 and 6 show the removal efficiency variations of $\mathrm{BOD}_{5}$ and $\mathrm{COD}$, respectively, over time. Table 5 shows the average removal efficiency (the average of the removal efficiencies calculated every five-day period, which is denoted graphically) for $\mathrm{BOD}_{5}$ and COD as well as overall removal efficiencies of these parameters based on the mass balance analysis. Average COD removal efficiencies for mixed-media and layered-media columns were $(60 \pm 9.1) \%$ and $(73 \pm 7.1) \%$, respectively. Mixedmedia and layered-media columns showed $(84 \pm 14.2) \%$ and $(83 \pm 10.9) \%$ respectively, for average $\mathrm{BOD}_{5}$.

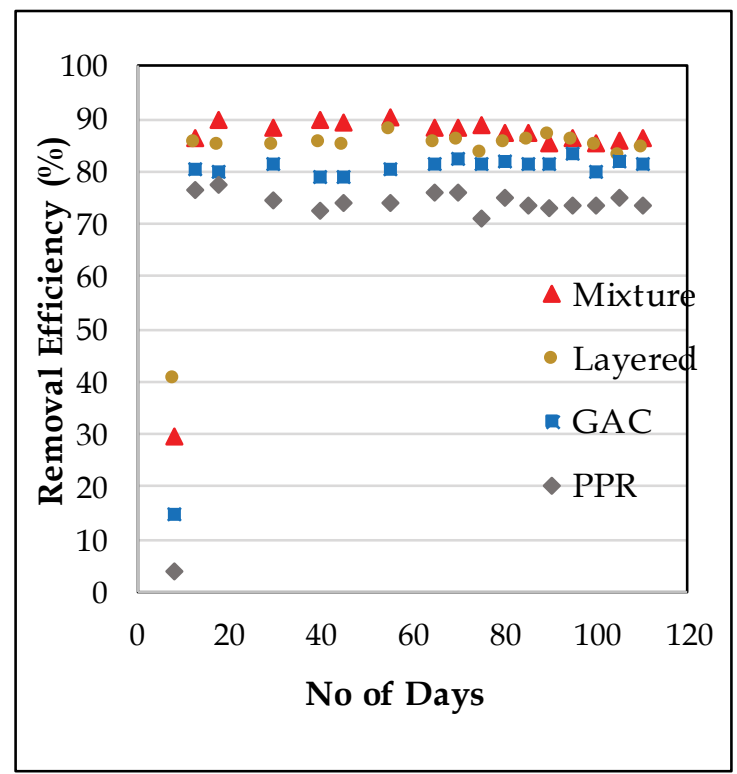

Figure 5 - Variation of BOD5 Removal Efficiency

Being a well-known adsorbent for organic materials, the high removal efficiency in GAC media could be dominated by adsorption.
Bodik et al. [6] reported that the $\mathrm{BOD}_{5}$ removal is around $68 \%$ with the plastic polar ring media, however, in the present study, PPR's average removal efficiency for $\mathrm{BOD}_{5}$ was $70 \%$, which is slightly higher. The organic materials such as FWC in the experimental filter columns could provide some adsorption sites, and serve as energy sources for the microorganisms [16]. Therefore, adsorption may have taken place inside the filter columns at the initial stage, going by the adsorption theory mentioned in [17]. The removal rate can reduce due to the decrease in the rate of adsorption. However, the removal rate was at a higher value throughout the experiment. This could be due to microbial decomposition at the latter stage that may have constructively contributed to maintain the removal efficiency.

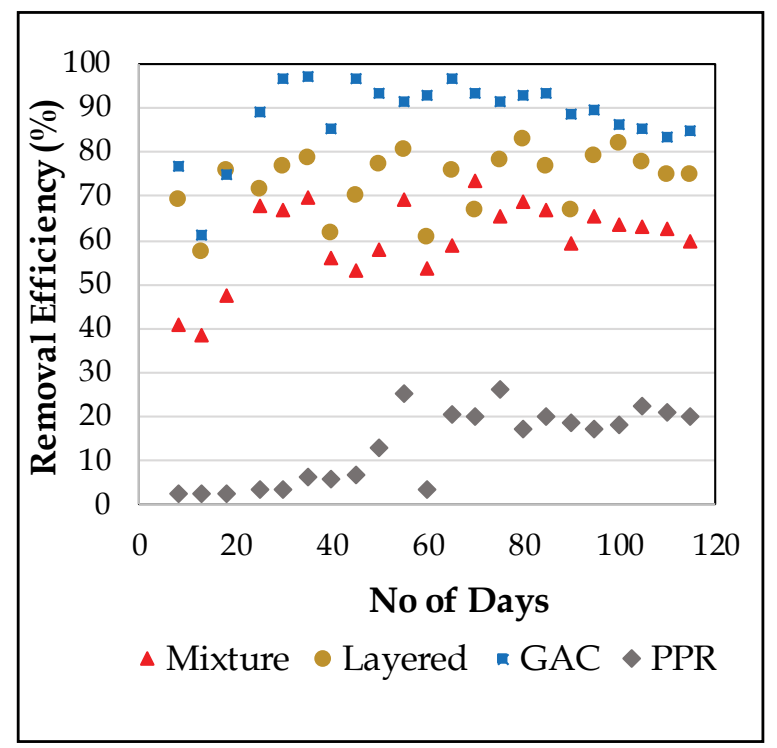

Figure 6 - Variation of COD Removal Efficiency

Table 5 - Removal Efficiencies of BOD5 and COD

\begin{tabular}{|c|c|c|c|}
\hline $\begin{array}{c}\text { Paramete } \\
\mathrm{r}\end{array}$ & $\begin{array}{c}\text { Mixture } \\
(\%)\end{array}$ & $\begin{array}{c}\text { Layered } \\
(\%)\end{array}$ & GAC (\%) \\
\hline $\begin{array}{c}\text { COD } \\
\text { (Avg.) }\end{array}$ & $60 \pm 9.1$ & $73 \pm 7.1$ & $88 \pm 8.5$ \\
\hline $\begin{array}{c}\text { COD } \\
\text { (Overall) }\end{array}$ & 59 & 73 & 88 \\
\hline $\begin{array}{c}\text { BOD5 } \\
\text { (Avg.) }\end{array}$ & $84 \pm 14.2$ & $83 \pm 10.9$ & $77 \pm 16.1$ \\
\hline $\begin{array}{c}\text { BOD5 } \\
\text { (Overall) }\end{array}$ & 87 & 84 & 79 \\
\hline
\end{tabular}

3.2 Removal of Nitrogenous Compounds Table 6 shows the nitrogenous compound removal efficiencies (average and overall). The definitions for average and overall removal efficiencies are similar to the description given 
in Section 3.1. Figure 7 and Figure 8 show the variation of removal efficiencies of $\mathrm{TN}$ and Ammonia-N respectively, with time. According to both the Figures and the Table, experimental units performed better in removing nitrogenous compounds than that of PPR. Nanayakkara et al. [10] [11] studied the behavior of anaerobic filters using FWC, DAS and WSS as individual materials and they achieved removal of $83.28 \%$, $74.34 \%$ and $78.11 \%$, respectively. The results obtained from that study were slightly higher than those of the present study.

The removal efficiency of $\mathrm{TN}$ for all the media was quite stable throughout the experimental period. According to the influent characteristics, nearly half the percent of influent TN represents nitrate nitrogen. Hence, the reduction of $\mathrm{TN}$ could mainly be due to denitrification, which occurs in an anoxic environment with the presence of a carbon source. All the reactors had a supporting environment for above conditions. The other possible treatment mechanisms could be ammonia adsorption.

Table 6 - Removal Efficiencies of $\mathrm{NH}_{3}-\mathrm{N}$ and TN

\begin{tabular}{|c|c|c|c|c|}
\hline Parameters & 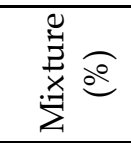 & 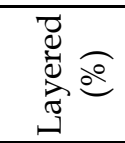 & $\underset{\cup}{\cup} \overparen{e}$ & $\begin{array}{l}\frac{a}{\partial} \\
\frac{a}{a} \\
\frac{a}{a}\end{array}$ \\
\hline TN (Avg) & $50 \pm 7.2$ & $60 \pm 14.0$ & $92 \pm 3.1$ & $12 \pm 4.5$ \\
\hline $\begin{array}{c}\text { TN } \\
\text { (Overall) }\end{array}$ & 49 & 61 & 92 & 12 \\
\hline $\begin{array}{c}\mathrm{NH}_{3}-\mathrm{N} \\
(\mathrm{Avg})\end{array}$ & $22 \pm 16.4$ & $56 \pm 11.1$ & $91 \pm 3.3$ & $16 \pm 10.5$ \\
\hline
\end{tabular}

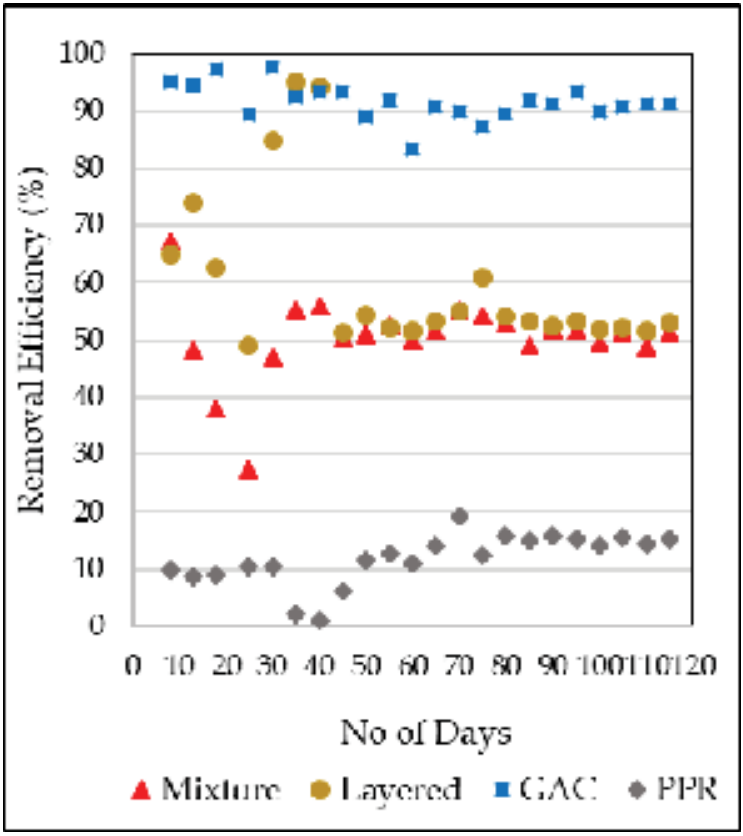

Figure 7 - Variation of TN Removal Efficiency

\subsection{Removal of Phosphorus Compounds}

Table 7 shows the phosphorus compound removal efficiencies (average and overall). The definitions for average and overall removal efficiencies are similar to the description given in Section 3.1. The mixed-media and layered columns showed average TP removal efficiencies of $71 \%$ and $75 \%$, respectively. The average $\mathrm{PO}_{4}{ }^{3-} \mathrm{P}$ removal efficiencies of mixed, layered and PPR are $77 \%, 78 \%$ and $78 \%$, respectively. Figures 9 and 10 depict the variation of removal efficiencies of TP and $\mathrm{PO}_{4}{ }^{3-}-\mathrm{P}$, respectively. The removal efficiency of the experimental units was on a par with that of the PPR. The anaerobic environment inside reactors could cause biological phosphorus removal [17]. GAC control column possessed negative removal efficiencies.

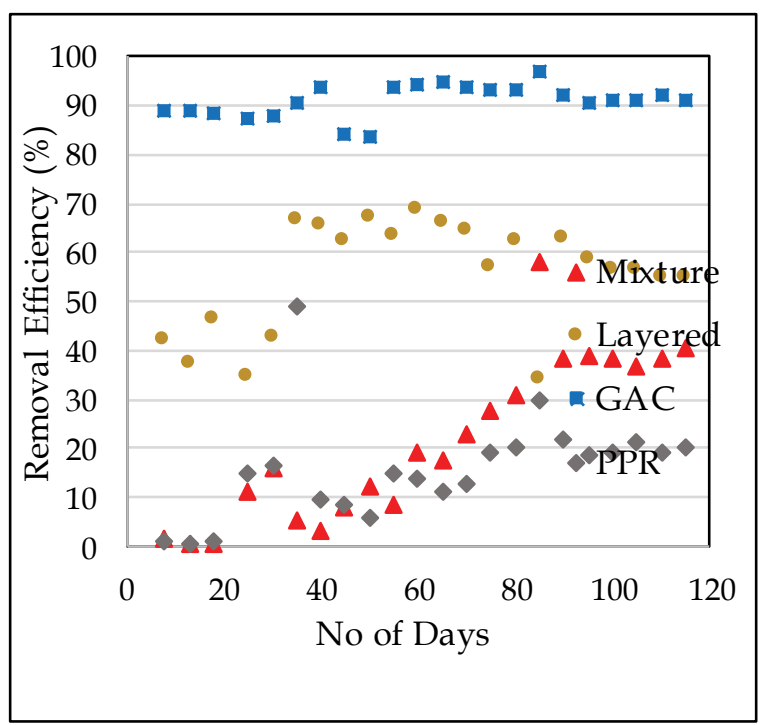

Figure 8 - Variation of $\mathrm{NH}_{3}-\mathrm{N}$ Removal Efficiency

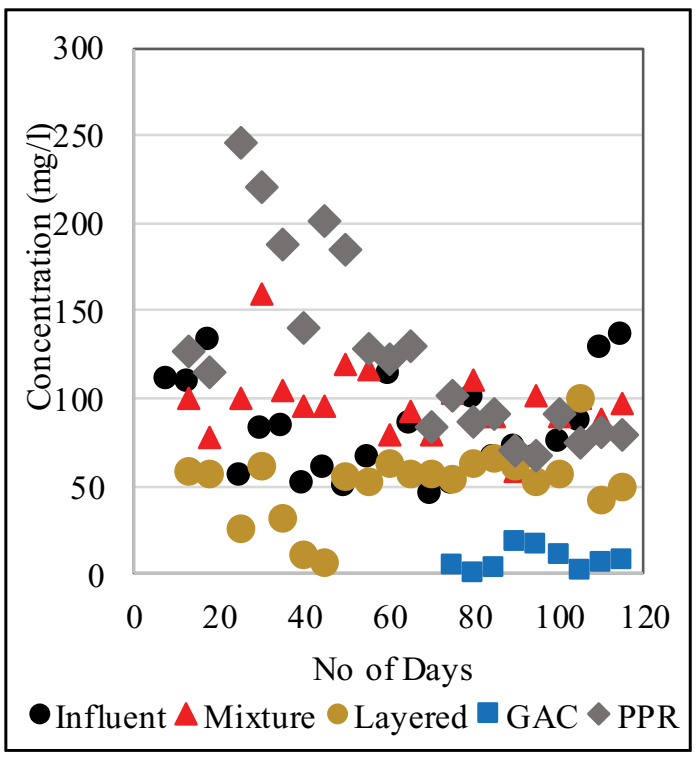

Figure 9 - Variation of $\mathrm{NO}_{2}-\mathrm{N}$ Concentration in Effluent 
Table 7 - Removal Efficiencies of TP and $\mathrm{PO}_{4}{ }^{3-}-\mathrm{P}$

\begin{tabular}{|c|c|c|c|}
\hline Parameter & $\begin{array}{c}\text { Mixture } \\
(\%)\end{array}$ & $\begin{array}{c}\text { Layered } \\
(\%)\end{array}$ & $\begin{array}{c}\text { PPR } \\
(\%)\end{array}$ \\
\hline TP (Avg.) & $71 \pm 3.9$ & $75 \pm 7.3$ & $70 \pm 4.2$ \\
\hline $\mathrm{TP}$ (Overall) & 71 & 76 & 70 \\
\hline $\mathrm{PO}_{4}{ }^{3-\mathrm{P}}$ (Avg.) & $77 \pm 9.6$ & $78 \pm 9.3$ & $78 \pm 9.2$ \\
\hline $\mathrm{PO}_{4}{ }^{3-\mathrm{P}}$ (Overall) & 78 & 79 & 79 \\
\hline
\end{tabular}

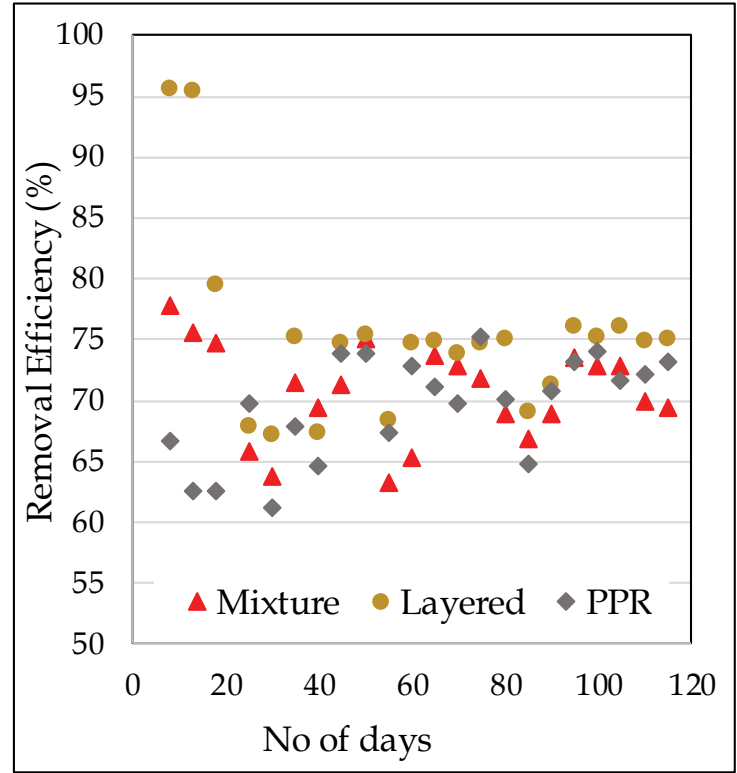

Figure 10 - Variation of TP Removal Efficiency

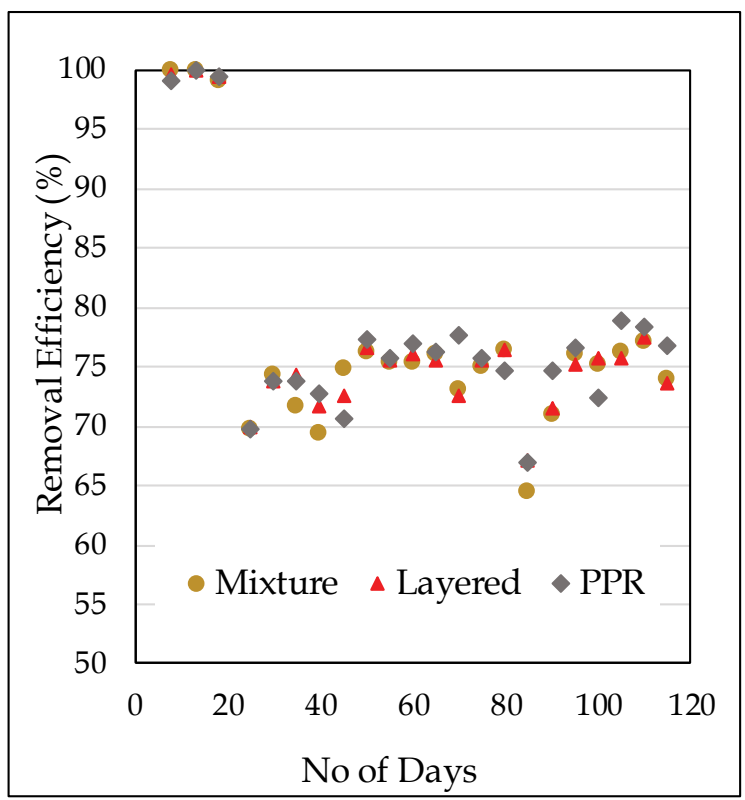

Figure 11 - Variation of $\mathrm{PO}_{4}^{3--P}$ Removal Efficiency

\subsection{Removal of Heavy Metals}

Table 8 shows the heavy metals $(\mathrm{Pb}, \mathrm{Cd}, \mathrm{Cu}$ and $\mathrm{Mn}$ ) removal efficiencies (average and overall). The definitions for average and overall removal efficiencies are similar to the description given in section 3.1. Figures 12, 13, 14 and 15 depict the variation of the removal efficiencies of $\mathrm{Pb}, \mathrm{Cd}, \mathrm{Cu}$ and $\mathrm{Mn}$, respectively. The treatment performances of the mixed and layered experimental columns were comparatively good. Both the columns surpassed the performances of the column with PPR. Their performances lagged behind the column with GAC for measured heavy metals, but not for Total Dissolved Solids (TDS) (Figure 14), for which the removal efficiencies were negative values. The conductivity of the effluent of GAC column (Figure 15) is considerably higher than that of the influent, implying a possible addition of metallic compounds into the solution. Zhao et al. [18] stated that sorption is considered as a very effective and economical process for metal iron removal from wastewater. In addition, ion exchange and chemical precipitation are other treatment mechanisms possible in a porous media. Owing to the chemical properties of DAS $\left(\mathrm{Al}_{2}(\mathrm{SO} 4)_{3}\right)$ and WSS $\left(\mathrm{SiO}_{2}\right)$ in the experimental media, mixed and layered media gave considerable removal efficiencies. Zhao et al.[18] explained the great potential that a bio sorbent has in adsorbing heavy metals. The high removal efficiencies resulted in mixed and layered media prove the above statement.

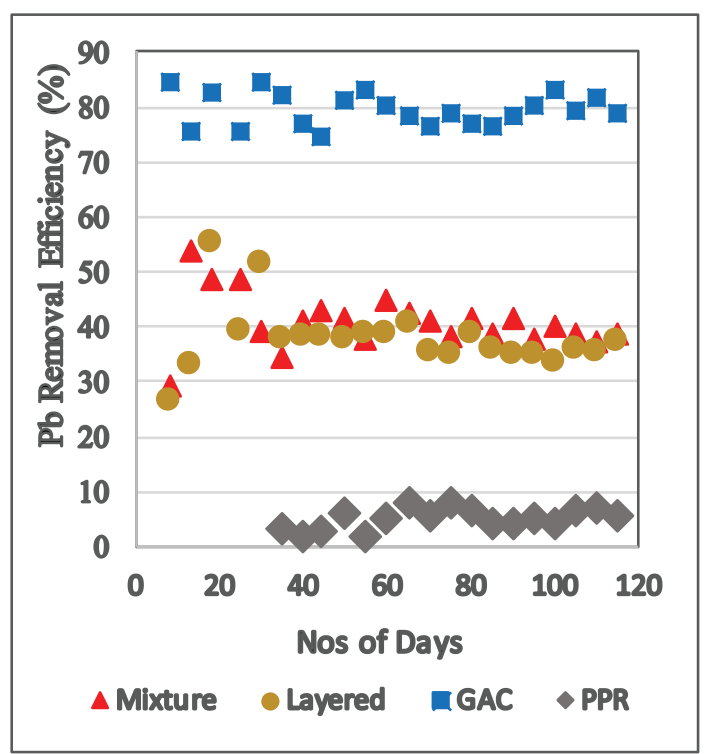

Figure 12 - Variation of $\mathrm{Pb}$ Removal Efficiency 


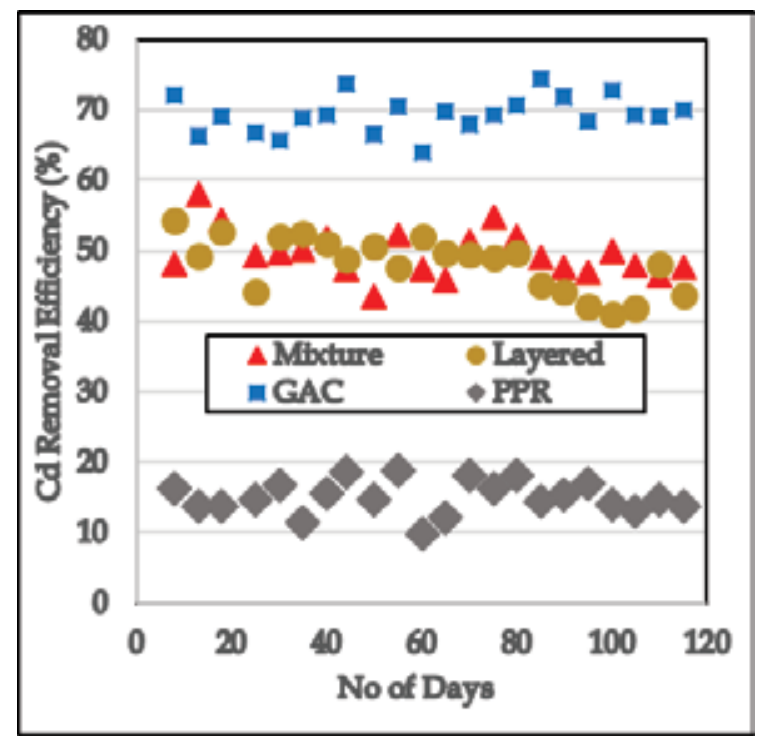

Figure 13 - Variation of Cd Removal Efficiency

Table 8 - Removal Efficiency (\%) of Heavy Metals

\begin{tabular}{|c|c|c|c|c|}
\hline \multirow{2}{*}{ 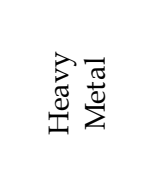 } & $\begin{array}{l}\text { Mixed } \\
\text { Media }\end{array}$ & $\begin{array}{c}\text { Layered } \\
\text { Media }\end{array}$ & GAC & PPR \\
\hline & 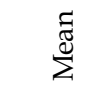 & 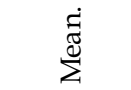 & $\stackrel{\Xi}{\Xi}$ & $\sum_{\mathbb{\Xi}}^{\mathbb{Z}}$ \\
\hline $\mathrm{Pb}$ (Avg.) & $\begin{array}{c}40.9 \pm 5 \\
.1\end{array}$ & $37.8 \pm 5.8$ & $79.6 \pm 3.0$ & $5.0 \pm 2.0$ \\
\hline $\begin{array}{c}\mathrm{Pb} \\
\text { (Overall) }\end{array}$ & 40 & 37 & 80 & 5 \\
\hline Cd (Avg.) & $\begin{array}{c}49.6 \pm 3 \\
.3 \\
\end{array}$ & $48.2 \pm 3.9$ & $69.4 \pm 2.6$ & $15.1 \pm 2.4$ \\
\hline $\begin{array}{c}\mathrm{Cd} \\
\text { (Overall) } \\
\end{array}$ & 48 & 54 & 71 & 15 \\
\hline $\mathrm{Cu}$ (Avg.) & $\begin{array}{c}47.2 \pm 6 \\
.3 \\
\end{array}$ & $49.4 \pm 4.7$ & $75.3 \pm 5.8$ & $8.4 \pm 3.7$ \\
\hline $\begin{array}{c}\mathrm{Cu} \\
\text { (Overall) }\end{array}$ & 41 & 45 & 69 & 5 \\
\hline Mn (Avg.) & $\begin{array}{c}52.4 \pm 4 \\
.1\end{array}$ & $58.1 \pm 5.0$ & $74.1 \pm 6.4$ & $11.2 \pm 4.4$ \\
\hline $\begin{array}{c}\text { Mn } \\
\text { (Overall) }\end{array}$ & 52 & 57 & 71 & 9 \\
\hline
\end{tabular}

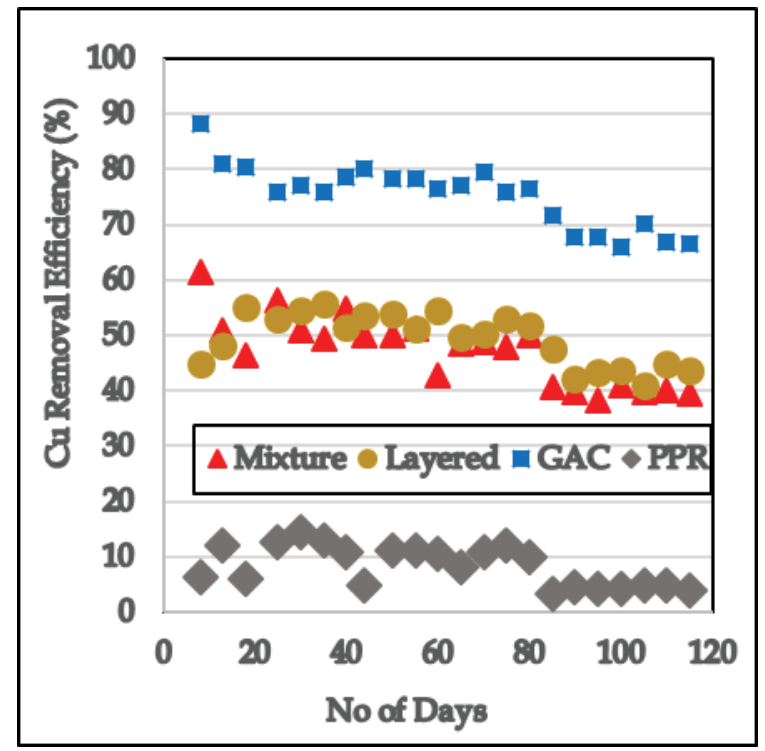

Figure 14 - Removal Efficiency of $\mathrm{Cu}$
3.5 Variation of the Physical and Mechanical Properties

In order to find successful filter materials, it is important to investigate the material properties of filters. The filters may not meet expected achievements due to several inferior facts like a high pressure drop, an increase in resistance to flow, poor mechanical characteristics and unacceptable particulate emissions. However, the above factors lead to an under-performing filter and result in lesser life than expected. In order to prevent this kind of situation, a careful evaluation of the filter media needs to be performed.

Figure 17 shows the sieve analysis of the materials before loading and after unloading. Table 9 shows the physical and mechanical properties before and after the experimental run.

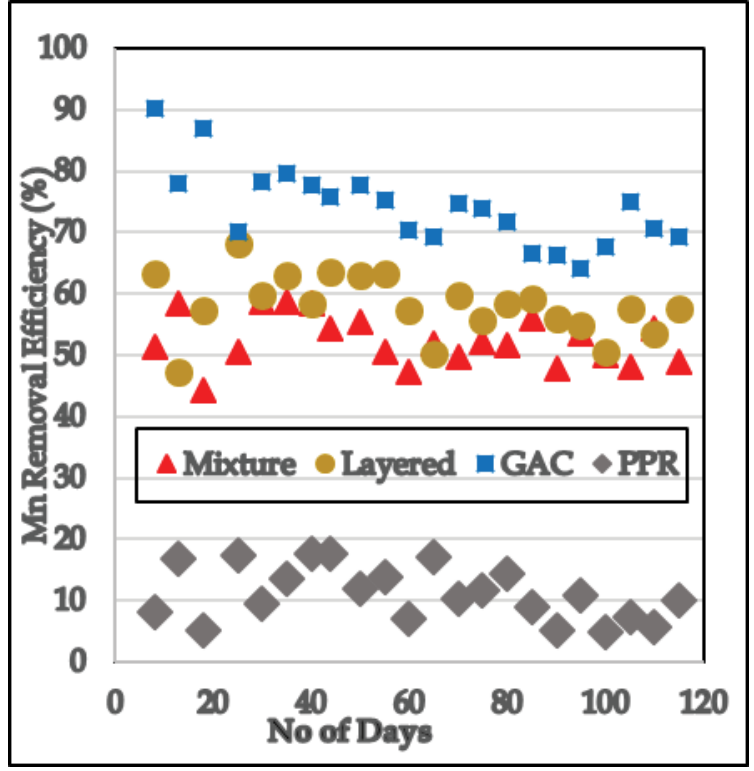

Figure 15 - Removal Efficiency of Mn

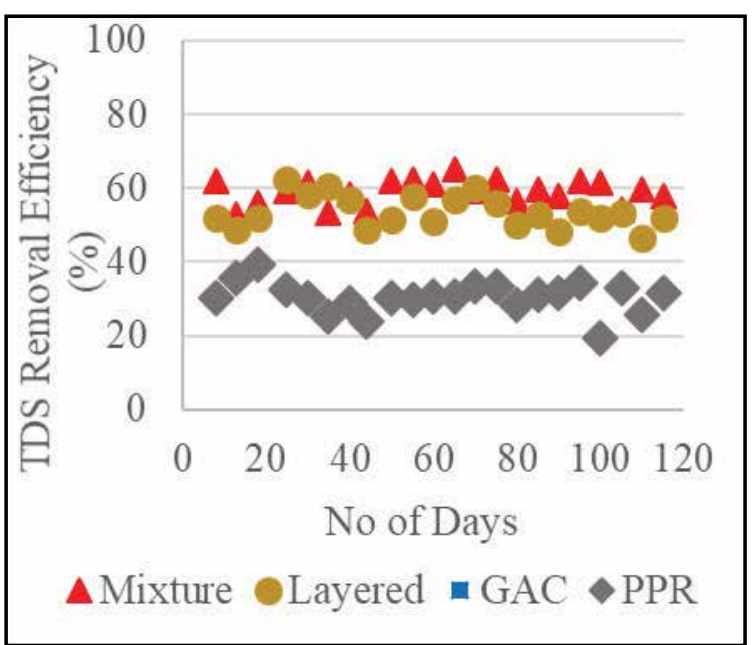

Figure 16 - Removal Efficiency of TDS 
With the leachate interaction, the specific gravity of all the experimental materials slightly increased with the decrease of void volume ratio. The effective diameter of WSS and DAS slightly decreased while that of FWC slightly increased. Increment of effective diameter could be explained by the wearing process of the particles. There could also be particle breaking to small pieces during the leachate run. The increase of effective diameter could happen due to coagulation, flocculation and sedimentation of particles with the leachate interaction.

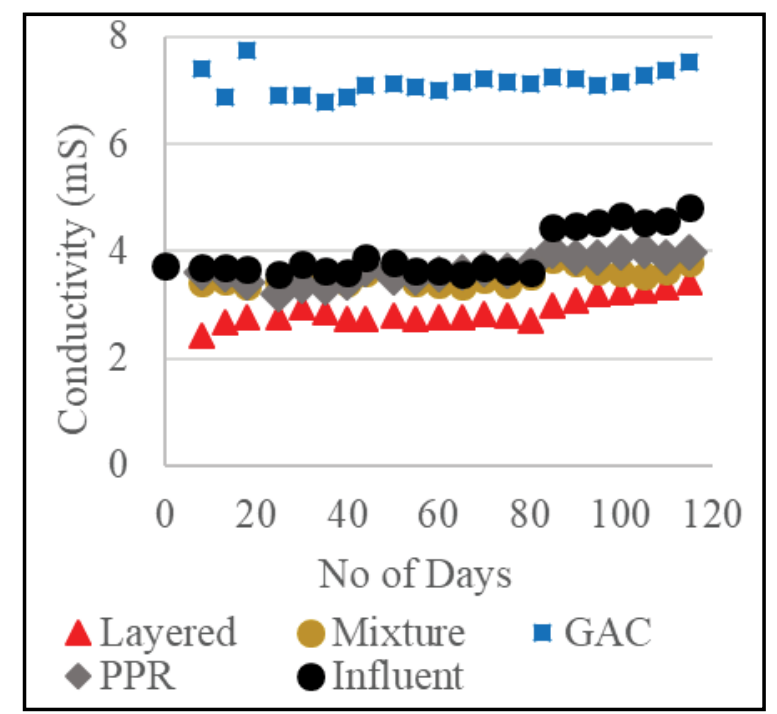

Figure 17 - Variation of Conductivity

The hydraulic conductivity, which is in the order of magnitude of $10^{-3}$, obtained from the constant head method decreased with the experimental run. Therefore, particles have clogged due to coagulation and flocculation of the media when leachate interaction occurs. This may result in void ratio reduction inside the column.

Table 9 - Initial and Final Material Properties

\begin{tabular}{|l|l|l|l|l|}
\hline \multicolumn{2}{|l|}{ Filtration Material } & FWC & DAS & WSS \\
\hline \multicolumn{2}{|c|}{} & & & \\
\hline \multirow{2}{*}{$\mathrm{C}_{\mathrm{u}}$} & Initial & 1.93 & 1.72 & 2.2 \\
\cline { 2 - 5 } & Final & 1.89 & 2.05 & 3.03 \\
\hline $\begin{array}{l}\text { Permeabi } \\
\text { lity } \\
(\mathrm{cm} / \mathrm{s})\end{array}$ & Initial & .00412 & 0.00397 & 0.0071 \\
\cline { 2 - 5 } & Final & .00391 & 0.00377 & $\begin{array}{l}0.0069 \\
1\end{array}$ \\
\hline $\begin{array}{l}\text { Specific } \\
\text { Gravity }\end{array}$ & Initial & 1.43 & 1.75 & 2.63 \\
\cline { 2 - 5 } & Final & 1.75 & 1.9 & 2.77 \\
\hline $\begin{array}{l}\text { Cohesion } \\
(\text { KN/m }\end{array}$ & Initial & - & 12.7 & 9.8 \\
\cline { 2 - 5 } $\begin{array}{l}\text { Final } \\
\text { Friction } \\
\text { Angle } \\
(\mathrm{o})\end{array}$ & Initial & - & 19.8 & 13.3 \\
\cline { 2 - 5 } & Final & - & 24 & 32 \\
\hline
\end{tabular}

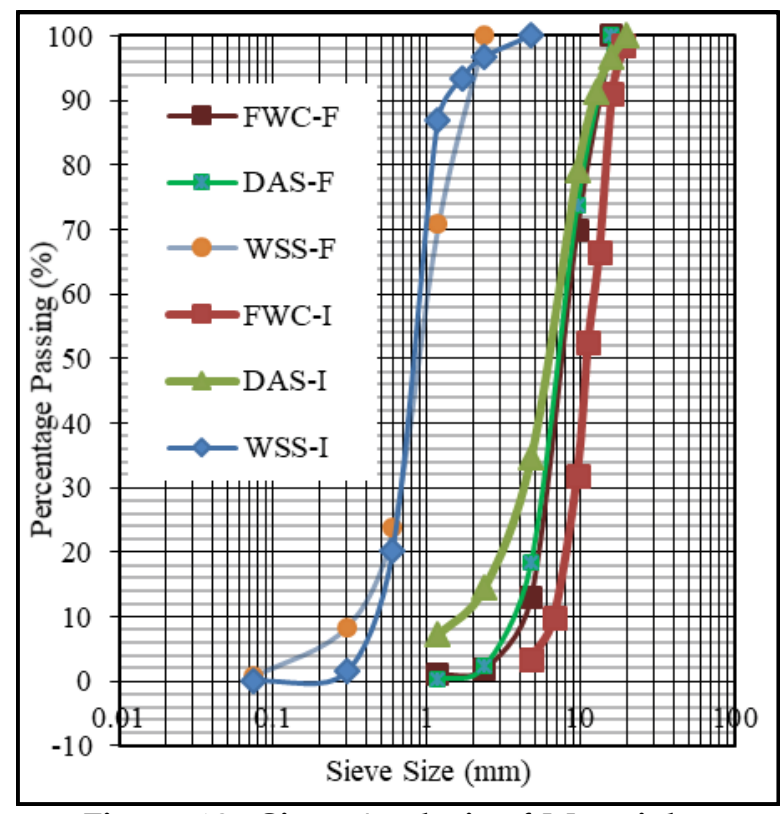

Figure 18 - Sieve Analysis of Materials

(I-Before Loading; F- After Unloading)

\section{Conclusions}

The treatment potentials of DAS, WSS and FWC for organic, nitrogenous and phosphorus compounds and heavy metals were studied and compared with those of conventional expensive filter materials, namely GAC and PPR. After the initial 10 days, the removal efficiencies of $\mathrm{BOD}_{5}$ in the mixed and layered media made of above low-cost materials, became more than $80 \%$, and remained more or less the same until the end of the run at 115 days. The treatment performance is more than that of both GAC and PPR. The removal efficiency of COD in the layered media was about $73 \%$, which is a way higher value than that of PPR and a slightly lower than that of GAC. The mixed-media is also higher than that of PPR. The results provide evidence for the occurrence of adsorption and biodegradation.

The treatment potential of the experimental materials for nitrogenous compounds such as $\mathrm{TN}$ and $\mathrm{NH}_{3}-\mathrm{N}$ is also greater than that of PPR and less than that of GAC. The layered arrangement performed better. The occurrence of denitrification and ammonium adsorption can be proved by the pattern of variation of the removal efficiencies. The treatment potential for phosphorus compounds of the experimental filter materials is on a par with that of PPR, whereas the values obtained for GAC were negative values. The presence of DAS in the experimental media could be the major cause of high removal efficiency. It can also be imagined that biological phosphorus removal could be 
dominant given the environment inside reactors were anaerobic.

The treatment efficiencies of experimental columns for $\mathrm{Pb}, \mathrm{Cd}, \mathrm{Cu}$ and $\mathrm{Mn}$ have an average value of $50 \%$, which is far greater than that of PPR, however less than that of GAC. The removal efficiencies of TDS by GAC are negative, whereas the conductivity of the effluent from GAC column is far higher than the conductivity of the influent. This clearly indicates the shortcomings associated with GAC when used as a filter media addressing treatment of a range of contaminants.

Hence, the results reveal that the selected lowcost filter materials are able to treat organic, nitrogenous and phosphorus compounds, several heavy metals and TDS in one reactor. Though the treatment efficiency of GAC for organic and nitrogenous compounds and heavy metals is very high, it is not applicable for phosphorus compounds and TDS. The increment of the conductivity value is also a problem. Further, the present results show that PPR is good at removing only $\mathrm{BOD}_{5}$ and phosphorus compounds.

Both layered and mixed arrangements of above filter materials can effectively be utilized in anaerobic filters, whereas layered arrangement performed better in all except $\mathrm{Pb}$ removal.

It can be concluded that a down-flow anaerobic filter using low-cost materials with layered configuration is applicable to give partial treatment to organic, nitrogenous and phosphorus compounds, heavy metals, namely $\mathrm{PB}, \mathrm{Cd}, \mathrm{Cu}$ and $\mathrm{Mn}$ in landfill-leachate. The small changes of the physical and mechanical properties of the experimental filter materials during the experimental period having a duration of 115 days, also certify the long-term applicability of the selected materials. The useful application of waste material such as DAS in anaerobic filters is a way of reusing it, which would have otherwise caused issues in disposing.

\section{Acknowledgement}

The authors wish to acknowledge the assistance given by Ms D.A.M. Nimal Shanthi, Technical Officer of the Environmental Engineering Laboratory, Department of Civil and Environmental Engineering, Faculty of Engineering, University of Ruhuna, Hapugala, Galle.

\section{References}

1. Mahmoudkhani, R., Hassani, A. H. and Borghei, S. M., "Study on Anaerobic Landfill Leachate Treatability by Membrane Bioreactor", International Conference on Biology, Environment and Chemistry, IACSIT press, Singapore, 2011.

2. Moulin, P., Renou, S., Givaudan, J. G., Poulain, S. and Dirassouyan, F., "Landfill Leachate Treatment: Review and Opportunity", Hazardous Materials. 150(2008), pp. 468-493.

3. Mojiri, A., Aziz, H. A. and Aziz, S. Q., “Trends in Physical-Chemical Methods for Landfill Leachate Treatment", Int J Sci Res Environ Sci, 2013, 1, pp.16-25.

4. Wiszniowski, J., Robert, D., Surmacz-Gorska, J., Miksch, K. and Weber, J. V., "Landfill Leachate Treatment Methods: A Review", Environmental Chemistry Letters, 2005, 4(1), pp. 51-61.

5. Aziz, H. A., Foul, A. A, Isa, M. H., and Hung, Y., "Primary Treatment of Anaerobic Landfill Leachate using Activated Carbon and Limestone: Batch and Column Studies", Environment and Waste Management 4(2009), pp. 282-298.

6. Abbas, A. A., Jinhsong, G., Ping, L. Z., Ying-Ya, P. and Al-Rekabi, W. S., "Review on Landfill Leachate Treatments", American Journal of Applied Sciences, 2009, 6(4), pp. 672-684.

7. Aziz, S. Q., Aziz, H. A., Bashir, M. J. K. and Mojiri, A., "Wastewater Engineering: Types, Characteristics and Treatment Technologies Municipal Landfill Leachate Treatment Techniques: An Overview", Wastewater Engineering: Types, Characteristics and Treatment Technologies, 2014.

8. Fia, R., Schuery, F. C., De Matos, A. T., Fia, F. R. L. and Borges, A. C., "Influence of Flow Direction in the Performance of Anaerobic Filters", 2012, Acta Scientiarum 34(2), pp. 141-147.

9. Vidanapathirana, V. P. H. S., Siriwardana, M. P., Nanayakkara, B. S. R. and Dayanthi, W. K. C. N.; "Down-Flow Anaerobic Filters Packed with Organic and Inorganic Waste Matter to Treat Landfill-Leachate"; Proceedings of the Special Session on Urban Water Environment Monitoring and Management, 4th International Conference on Structural Engineering and Construction Management 2013; Kandy;13-15 December 2013, pp 50-57.

10. Nanayakkara, B. S. R., Dayanthi, W. K. C. N, Vidanapathirana, V. P. H. S and Siriwardana, M. P., "Up and Down- Flow Anaerobic Filters Using Firewood Charcoal, Dewatered Alum 
Sludge and Silica Sand for Landfill-Leachate Treatment", Annual Transactions of IESL, 2014.

11. Nanayakkara, B. S. R. and Dayanthi, W. K. C. N., "Landfill-Leachate Treatment in Up and Down Flow Anaerobic Filters with Combined Packing Media of Locally Available and Low-Cost Materials", 14th Academic Sessions, University of Ruhuna, 2017.

12. Dayanthi, W. K. C. N., Ranga, U. K. S. and Sanjeevani, H. K. M., “Applicability of Low-Cost Organic Materials as Packing Media in Anaerobic Filters to Treat Landfill Leachate", Annual Transactions of IESL, 2013, pp. [72-79].

13. Dayanthi, W. K. C. N., Nanayakkara, B. S. R., Kawamoto, K., Premathilaka, M. D. B. A. and Dulvin, O. V. N.; "Field-Scale Study on Treating Landfill Leachate Using Anaerobic Filters Packed with Low-Cost Filter Media"; 2017, Transactions 2017, Institution of Engineers, Sri Lanka (IESL); Volume 1-Part B, pp-531-536.

14. Standard Methods for the Examination of Water and Wastewater, American Public Health Association, 1015 Fifteenth Street, NW, Washington, DC, USA, pp.4500-5220, 1988.

15. Young, J. C. and McCarty, P. L., "The Anaerobic Filter for Waste Treatment", Stanford University Technical Report No 87, 1968.

16. Bagchi, A., "Design of Landfills and Integrated Solid Waste Management", John Wiley \& Sons, Inc., 2004.

17. Metcalf $\mathcal{E}$ Eddy, "Wastewater Engineering: Treatment $\mathcal{E}$ Reuse", 4th ed., Tata McGraw-Hill, Inc., 2003.

18. Zhao, G., Wu, X., Tan, X. and Wang, X., "Sorption of Heavy Metal Ions from Aqueous Solutions: A Review". The Open Colloid Science Journal, 2011, 4, 19-31. 